Article

\title{
Encapsulation of Lacticaseibacillus rhamnosus GG: Probiotic Survival, In Vitro Digestion and Viability in Apple Juice and Yogurt
}

\author{
Oscar O. Romero-Chapol ${ }^{1}$ (D) Abigail Varela-Pérez ${ }^{1}$, Ana G. Castillo-Olmos 1(D), Hugo S. García ${ }^{1}$ (D), \\ Jaspreet Singh $^{2}$, Pedro J. García-Ramírez ${ }^{3} \mathbb{D}$, Rubí Viveros-Contreras ${ }^{4}$, Claudia Y. Figueroa-Hernández ${ }^{5, * \mathbb{D}}$ \\ and Cynthia Cano-Sarmiento ${ }^{5, *}$
}

check for updates

Citation: Romero-Chapol, O.O.; Varela-Pérez, A.; Castillo-Olmos, A.G.; García, H.S.; Singh, J.; GarcíaRamírez, P.J.; Viveros-Contreras, R.; Figueroa-Hernández, C.Y.; CanoSarmiento, C. Encapsulation of Lacticaseibacillus rhamnosus GG: Probiotic Survival, In Vitro Digestion and Viability in Apple Juice and Yogurt. Appl. Sci. 2022, 12, 2141. https://doi.org/10.3390/ app12042141

Academic Editor: María de Jesús Perea-Flores

Received: 21 January 2022

Accepted: 16 February 2022

Published: 18 February 2022

Publisher's Note: MDPI stays neutral with regard to jurisdictional claims in published maps and institutional affiliations.

Copyright: (C) 2022 by the authors. Licensee MDPI, Basel, Switzerland. This article is an open access article distributed under the terms and conditions of the Creative Commons Attribution (CC BY) license (https:// creativecommons.org/licenses/by/ $4.0 /)$.
1 Tecnológico Nacional de México/Instituto Tecnológico de Veracruz, Unidad de Investigación y Desarrollo en Alimentos, M.A. de Quevedo 2779, Veracruz 91897, Veracruz, Mexico; oscarosiel.rocha@outlook.com (O.O.R.-C.); abigail_2365@hotmail.com (A.V.-P.); anagpe_ibq@outlook.com (A.G.C.-O.); hugo.gg@veracruz.tecnm.mx (H.S.G.)

2 School of Food and Advanced Technology, Massey University, Private Bag 11222, Palmerston North 4442, New Zealand; j.x.singh@massey.ac.nz

3 Instituto de Ingeniería, Universidad Veracruzana, Juan Pablo II s/n, Boca del Río 94294, Veracruz, Mexico; jagarcia@uv.mx

4 Centro de Investigaciones Biomédicas, Universidad Veracruzana, Dr. Luis Castelazo Ayala S/N Indutrial Ánimas, Xalapa 91190, Veracruz, Mexico; ruviveros@uv.mx

5 CONACYT-Tecnológico Nacional de México/Instituto Tecnológico de Veracruz, Unidad de Investigación y Desarrollo en Alimentos, M. A. de Quevedo 2779, Veracruz 91897, Veracruz, Mexico

* Correspondence: claudia.fh@veracruz.tecnm.mx (C.Y.F.-H.); cynthia.cs@veracruz.tecnm.mx (C.C.-S.)

\begin{abstract}
This study was aimed to prepare and characterize capsules loaded with Lacticaseibacillus rhamnosus GG (LGG), evaluating cell viability under gastrointestinal in vitro conditions and during storage in yogurt and apple juice, an alternative to traditional probiotic foods for people who are lactose intolerant. The capsules were prepared by ionic gelation, with an emulsification process as pretreatment. Cell viability of encapsulated LGG was evaluated after two different homogenization processes: magnetic stirring (AM) and Ultraturrax ${ }^{\circledR}$ homogenizer (UT). The system with the best relationship between viability and morphology was UT, which produced a viability of $85.80 \%$. During in vitro evaluation, the capsules provided higher protection than free cells, up to $100 \%$ of cell viability. The morphology of capsules of both systems displayed a continuous and homogeneous surface. The cell viability of the encapsulated probiotics added in apple juice stored for 22 days at $4{ }^{\circ} \mathrm{C}$ was $86.16 \%$ for AM and $100 \%$ for UT, while the viability of free cells was $80.50 \%$. In natural yogurt, the cell viability of the probiotics encapsulated stored 30 days at $4{ }^{\circ} \mathrm{C}$ was $100 \%$ for AM, $100 \%$ for UT, and $92.68 \%$ for free cells. This study suggests an alternative to preserve probiotic bacteria in a potential functional food.
\end{abstract}

Keywords: probiotic; encapsulation; viability; Lacticaseibacillus rhamnosus GG

\section{Introduction}

Probiotics, present in the intestinal microbiota, are defined as "live microorganisms which when administered in adequate amounts confer a health benefit on the host" [1]. Some bacteria of the Lactobacillus, Lacticaseibacillus, and Bifidobacterium genus considered probiotics are used in various clinical treatments and food products that have a benefit for consumer health. It has been proven that certain strains of Lacticaseibacillus rhamnosus (such as Lacticaseibacillus rhamnosus GG) have an anti-obesity effect when consumed as an adjuvant in high-fat diets in in vivo models, obtaining a decrease in weight and the amount of abdominal fat [2-4]. Lacticaseibacillus rhamnosus GG (LGG) is a Gram-positive, facultatively anaerobic, non-spore-forming bacterium that, although it is mesophilic, it is 
known that some strains can grow at temperatures below $15^{\circ} \mathrm{C}$ and above $40{ }^{\circ} \mathrm{C}$. LGG is a strain isolated from the feces of healthy adults. Its probiotic potential is related to an elevated adhesion capacity than other strains of the same species in the intestinal mucosa and the descending colon. This potential activity is more noticeable in newborns given their low resistance to colonization caused by a less diverse microbiota [5-7]. Within the host, Lacticaseibacillus rhamnosus GG displays various mechanisms of action, some as a consequence of the metabolism of certain short-chain fatty acids, such as acetate, propionate, and butyrate, which result in improvement of lipid metabolism, appetite control, and greater insulin sensitivity. In addition, it possesses mechanisms of modulation of enzymes involved in hepatic lipogenesis, avoiding excessive lipid accumulation in the liver [8,9]. The efficiency of the probiotic effect of these bacteria lies in their survival to passage through the gastrointestinal tract before reaching their site of action in the human intestine. Encapsulation is a technique that arises as an alternative to protect and preserve these bacteria in order to maintain their viability during storage and the digestion process, thus favoring their addition to a food matrix. On the other hand, encapsulation of probiotic bacteria, different techniques such as extrusion, emulsification, spray drying, electrospinning, ionic gelation, among others, have been studied, obtaining size scales of macro and micro $[10,11]$. In this sense, the encapsulating materials favor the controlled release and provide different degrees of protection during digestion, thus generating an increase in cell viability and colonization greater than $1 \times 10^{6} \mathrm{CFU} / \mathrm{mL}$, a value that is within the consumption recommendations for this type of product $[12,13]$. Some methods employed in the encapsulation of bacteria can be combined to prepare capsules with better morphologies and provide more effective protection; within these, the production of capsules from alginate by ionic gelation combined with an emulsification pretreatment arises as a coupling of techniques feasible to encapsulate probiotic bacteria due to the practicality of the methods, the high compatibility with the matrix, the biodegradability of alginate, and the control of the operating conditions. In addition, the use of alginate as a dietary fiber with beneficial activity on the glucose and cholesterol levels and the use of surfactants such as Tween $80^{\circledR}$ as protectors of cell viability under conditions of gastric acidity has been reported [14-16].

Therefore, in the present study, coupled emulsification and ionic gelling were used to encapsulate Lacticaseibacillus rhamnosus GG in a sodium alginate matrix. Furthermore, morphological parameters of the capsules were measured, and the encapsulation efficiency was determined. The cell viability of encapsulated and free Lacticaseibacillus rhamnosus GG was also evaluated in an in vitro digestion system and during its storage in commercial food matrices (apple juice and yogurt) in order to investigate the encapsulation conditions that favor cell preservation against stress conditions and the possible interactions between the food matrix, the capsules, and the cellular content. Finally, during each stage of the study, the morphology of the capsules was analyzed using scanning electron microscopy (SEM).

\section{Materials and Methods}

\subsection{Preparation of Probiotic Bacteria}

Lyophilized Lacticaseibacillus rhamnosus GG cells (Microbiologics Inc., St. Cloud, MN, USA) were rehydrated in $100 \mathrm{~mL}$ of MRS broth (Sigma-Aldrich ${ }^{\circledR}$, St Louis, MO, USA) previously autoclaved (All-American 50X, Hillsville, VA, USA) before incubation at $37^{\circ} \mathrm{C}$ for $24 \mathrm{~h}$ at $200 \mathrm{rpm}$ (MaxQ Mini 4450 Shaker $^{\mathrm{TM}}$, Thermo Fisher Scientific ${ }^{\circledR}$, Asheville, NC, USA). Lacticaseibacillus rhamnosus GG was sub-cultured five times before its use in the study.

\subsection{Preparation of Capsules Loaded with Lacticaseibacillus rhamnosus GG}

The preparation of the encapsulating matrix and the encapsulation process was carried out following the methodology of Ding and Shah [17] with modifications in the amount of vegetable oil added to the mixture, the rpm used in the homogenization, and the dosage of the alginate in the calcium chloride solution. The encapsulating alginate matrix (Sigma-Aldrich $^{\circledR}$, St Louis, MO, USA) (ALG) consisted of $25 \mathrm{~mL}$ of bacterial suspension 
with a concentration greater than $1 \times 10^{10} \mathrm{CFU} / \mathrm{mL}$ of Lacticaseibacillus rhamnosus GG in combination with $100 \mathrm{~mL}$ of $3 \%$ sodium alginate $(w / v)$. Subsequently, $1 \mathrm{~mL}$ of Tween ${ }^{\circledR}$ 80 (Sigma-Aldrich ${ }^{\circledR}$, St Louis, MO, USA) and $100 \mathrm{~mL}$ of vegetable oil (Selecto BRAND ${ }^{\circledR}$, Xalapa, Mexico) were added. The pretreatments to which the mixture was subjected were ultra-turrax homogenizer (UT) (model T-25 digital Ultraturrax ${ }^{\circledR}$, IKA, Staufen, Germany) set at $4000 \mathrm{rpm}$ for $7.5 \mathrm{~min}$ and magnetic stirring (Corning PC-420D, NY) (AM) at $1150 \mathrm{rpm}$ for $10 \mathrm{~min}$. The emulsified mixture was dispersed in a $0.1 \mathrm{M}$ calcium chloride solution by dripping at $15 \mathrm{~cm}$ of the solution with a flow of $2.5 \mathrm{~mL} / \mathrm{min}$ with the help of a peristaltic pump (Ecoshell ${ }^{\circledR}$ RD100-01, Pharr, TX, USA) with YZ1515 head and silicone hose \#19 (Qilipump, Hebei, China). Once the capsules were formed, they were stored at $4{ }^{\circ} \mathrm{C}$ for $12 \mathrm{~h}$ before being used for further analysis [17-19].

\subsection{Viability of Lacticaseibacillus rhamnosus GG}

The viability of Lacticaseibacillus rhamnosus GG was determined by dissolving $1 \mathrm{~g}$ of capsules in PBS solution (phosphate buffer pH 7) for 15 min with shaking at $2000 \mathrm{rpm}$ (Vortex Genie-2, Scientific industries Inc., Bohemia, NY, USA). From this mixture, $100 \mu \mathrm{L}$ were used to make serial dilutions that were spread and counted in a Petri dish. In the case of free cells, the buffer addition and stirring steps were omitted, but the other procedures were maintained.

Equation (1) was used to calculate viability:

$$
\operatorname{EY}(\%)=\frac{N}{N_{0}} \times(100)
$$

where $N_{0}$ is the number of bacteria at the beginning of encapsulation, and $N$ is the number of bacteria released by the capsules $[16,18,20]$.

\subsection{Morphological Analysis of Free and Encapsulated Lacticaseibacillus rhamnosus GG}

The morphology and microstructure of the capsules, as well as the free bacteria, were visualized by scanning electron microscopy (SEM) using a Tescan ${ }^{\circledR}$ MIRA3 equipment (Brno, Czech Republic) following the technique of Silva et al. [21] with modifications in the voltage used and addition of a drying process at $25^{\circ} \mathrm{C}$ in a biosafety cabinet (A2 1300 Series, Thermo Fisher Scientific ${ }^{\circledR}$, Asheville, NC, USA) prior to visualization by SEM. The samples were placed on carbon tape and left to dry for one hour in a laminar flow cabinet prior to inspection. Finally, the voltage was set at $10 \mathrm{kV}$ and $8 \mathrm{kV}$, respectively. It was worked under vacuum, using a secondary electron detector (SE) at $10 \mathrm{~mm}$ and $16 \mathrm{~mm}$ working distance. The images obtained by SEM were processed using the MIRA3 software version 4.2.19.1 (Tescan ${ }^{\circledR}$, Brno, Czech Republic) in TIFF format. Morphometric parameters such as Feret diameters, area, and circularity from the capsules were determined through digital image analysis in JPG format captured with a Nikon ${ }^{\circledR}$ D3200 camera (Minato, Tokyo, Japan) of 24.5 megapixels at $15 \mathrm{~cm}$ distance of the objective. For this analysis, an average of 100 capsules were placed in a Petri dish with a millimetric paper bottom. Digital image analysis was performed with ImageJ $1.52 \mathrm{q}$ software [22]. The circularity of the capsules was calculated with Equation (2) [23]:

$$
\text { Circularity }=\frac{4 \pi A}{P^{2}}
$$

where $A$ is the area of the capsule and $P$ is the perimeter. Values close to 1 indicate that the morphology of the capsule is geometrically close to a perfect circle. The visualization of the Lacticaseibacillus rhamnosus GG (LGG) cells was done using a DM2000 LED optical microscope (Leica Microsystems ${ }^{\circledR}$, Wetzlar, Germany) Leica Application Suite V4.9 software at $100 \times$ magnification after performing Gram staining. Free cells of LGG were visualized by SEM following the methodology previously described for capsules. 


\subsection{Preparation of Food Matrices Inoculated with Lacticaseibacillus rhamnosus GG: Yogurt and Juice}

Encapsulated and free bacteria were added to the commercial food matrices in a ratio of $10 \% w / v$ to determine the effect of food on the viability of bacteria during storage at $4{ }^{\circ} \mathrm{C}$ [24-26]. The products used were Jumex ${ }^{\circledR}$ Único Fresco ${ }^{\circledR}$ apple juice $(\mathrm{pH} 2.97 \pm 0.11)$ and Danone ${ }^{\circledR}$ natural yogurt (pH $3.99 \pm 0.02$ ). The viability of Lacticaseibacillus rhamnosus GG (LGG) was periodically monitored with the previously described Petri dish counting method adding a wash with sterile water before dissolving in PBS solution.

\subsection{Viability of Encapsulated and Free Lacticaseibacillus rhamnosus GG in Gastrointestinal Conditions In Vitro}

To simulate gastric conditions, the COST INFOGEST in vitro digestion technique was followed $[27,28]$. For the oral phase, $5 \mathrm{~g}$ of capsules were taken from each system, or free cells $(5 \mathrm{~mL})$ were mixed with $3.5 \mathrm{~mL}$ of salivary solution. An amount of $0.5 \mathrm{ml}$ of $\alpha$-amylase solution at $1500 \mathrm{U} / \mathrm{mL}, 25 \mu \mathrm{L}$ of $0.3 \mathrm{M} \mathrm{CaCl}_{2}$, and $975 \mu \mathrm{L}$ of distilled water were added to the mixture before incubation for $2 \mathrm{~min}$ at $37^{\circ} \mathrm{C}$. For the gastric phase, $7.5 \mathrm{~mL}$ of gastric solution, $1.6 \mathrm{~mL}$ of pepsin solution of $25000 \mathrm{U} / \mathrm{mL}$, and $5 \mu \mathrm{L}$ of $0.3 \mathrm{M} \mathrm{CaCl}_{2}$ were added. The $\mathrm{pH}$ of the solution was adjusted to $3 \pm 0.2$ with $1 \mathrm{M} \mathrm{HCl}$ and made up to $20 \mathrm{~mL}$ with distilled water. The gastric phase was incubated at $37^{\circ} \mathrm{C}$ for $2 \mathrm{~h}$. At the end of the gastric phase, the samples were cooled in an ice-water bath before preparing the intestinal phase. For the last stage, $11 \mathrm{~mL}$ of intestinal phase, consisting of $5 \mathrm{~mL}$ of $100 \mathrm{U} / \mathrm{mL}$ pancreatin, $40 \mu \mathrm{L}$ of $0.3 \mathrm{M} \mathrm{CaCl}_{2}$, and $2.5 \mathrm{~mL}$ of $9 \%$ bile solution were added. The $\mathrm{pH}$ was adjusted to $7 \pm 0.2$ with $1 \mathrm{M} \mathrm{NaOH}$ and made up to $40 \mathrm{~mL}$ with distilled water before incubation at $37^{\circ} \mathrm{C}$ for $2 \mathrm{~h}$ at $95 \mathrm{rpm}$. The reagents used to perform the in vitro evaluation were purchased from Sigma-Aldrich ${ }^{\circledR}$ (Steinheim, Germany); the solutions were incubated in the orbital shaker.

Aliquots were taken at the end of each stage for viability analysis by spreading in a Petri dish. Samples of the capsules were extracted for their visualization in SEM under the conditions previously described.

\subsection{Statistical Analysis}

Statistical analysis of the data was performed by analysis of variance (ANOVA) and means were compared using Tukey's test with the MiniTab 17.1 software (Minitab Inc., State College, PA, USA). The level of significance was defined as $p \leq 0.05$. The experiments were performed in duplicate; data entries represent the means \pm standard deviation (SD).

\section{Results and Discussion}

\subsection{Viability of Encapsulated Lacticaseibacillus rhamnosus GG}

The homogenization processes may create conditions that affect the cellular load of these systems. The AM and UT showed viabilities of $76.5 \%$ and $85.8 \%$, respectively (Table 1). Ding and Shah [17] carried out encapsulation of an alginate mixture with a similar composition to that employed in the present study, with different homogenization methods. These authors carried out the homogenization by Ultraturrax ${ }^{\circledR}$ at $4000 \mathrm{rpm}$ for $5 \mathrm{~min}$ and $10 \mathrm{~min}$, obtaining $59.9 \%$ and $58.1 \%$, respectively. When comparing data from the magnetic stirring method with those from these authors, a viability of $84.7 \%$ was reported after encapsulation, which differs from the $76.5 \%$ obtained in the present study in the AM system. The loss of viability in the AM system can be attributed to increased agitation and extended exposure. However, these authors mention that this is one of the most straightforward homogenization techniques, compatible with the encapsulation of bacteria. It is suggested that improvement in the response of cell viability in the system homogenized by Ultraturrax ${ }^{\circledR}$ can be attributed to the improvement of the stirring times and the modification of the formulation of the encapsulating matrix. 
Table 1. Viability of capsules loaded with Lacticaseibacillus rhamnosus GG produced by different treatments (AM and UT).

\begin{tabular}{cccc}
\hline Method & $\log$ CFU/mL ( N $\mathbf{0})$ & $\log$ CFU/mL (N) & Viability (\%) \\
\hline AM & $10.55 \pm 0.02^{\mathrm{a}}$ & $8.08 \pm 0.07^{\mathrm{b}}$ & 76.59 \\
UT & $10.55 \pm 0.03^{\mathrm{a}}$ & $9.05 \pm 0.13^{\mathrm{b}}$ & 85.80 \\
\hline
\end{tabular}

$\mathrm{AM}=$ magnetic stirring; UT $=$ Ultraturrax ${ }^{\circledR}$. Means \pm standard deviation $(\mathrm{SD})(p<0.05)$. Equal letters mean that there is no statistically significant difference.

In another study, Ribeiro et al. [29] performed the encapsulation of L. acidophilus LA-5 with a combination of ionic gelation with complex coacervation, the first homogenization (without bacteria) was made at $14000 \mathrm{rpm}$ for $5 \mathrm{~min}$, while after adding L. acidophilus LA-5 to the mixture a second homogenization was realized at $6000 \mathrm{rpm}$ for $1 \mathrm{~min}$. At the end of the encapsulation process, a viability of $82.8 \%$ was obtained, a value similar of that obtained in our study for the UT system (85.8\%), without the need to resort to an auxiliary coating technique. On the other hand, Zeashan et al. [30] implemented the extrusion to a $0.2 \mathrm{M} \mathrm{CaCl}_{2}$ solution of an alginate mixture (alone and mixed with soy protein) previously homogenized with a rotor-stator type equipment, obtaining viability percentages of $95 \%$ and $96 \%$, respectively, for Lactobacillus acidophilus.

In general, emulsification techniques in conjunction with ionic gelling of alginate mixtures have shown positive results in terms of viability, which is described in the studies reported by Ding and Shah [17], Patrignani et al. [19], and Sánchez et al. [31], where the use of these combined techniques produces viabilities greater than $80 \%$, a value attributed to the slight physical damage suffered by the cells during the manufacture of the emulsions when using operating conditions (pressure, agitation, time, or cycles) that do not pose additional stress to which the bacteria can be exposed as the heat generated during the process or mechanical shear. However, the use of high agitation speeds or pressure during the homogenization process results in smaller particle sizes, although the viability of bacteria is proportionally reduced [17,32].

\subsection{Morphological Analysis of Encapsulated and Free Lacticaseibacillus rhamnosus GG}

Strain morphology was carried out by microscopy to confirm the characteristics described in the literature for Lacticaseibacillus rhamnosus GG [7,33]. Its Gram-positive nature and one of the main characteristics of Lacticaseibacillus rhamnosus GG was confirmed: the link of bacilli in a branched form without mobility with sizes (per bacillus cell) in the range of 1 to $2 \mu \mathrm{m}$ in length (Figure 1 ).

The results obtained from the digital camera of the capsules loaded with Lacticaseibacillus rhamnosus GG with the ImageJ software are presented in Table 2.

Table 2. Morphological characteristics of capsules produced by AM and UT.

\begin{tabular}{cccc}
\hline Method & $\begin{array}{c}\text { Maximum Feret } \\
\text { Diameter }(\mathbf{m m})\end{array}$ & $\begin{array}{c}\text { Minimum Feret } \\
\text { Diameter }(\mathbf{m m})\end{array}$ & Circularity \\
\hline AM & $2.68 \pm 0.12^{\mathrm{a}}$ & $2.33 \pm 0.13^{\mathrm{a}}$ & $0.94 \pm 0.03^{\mathrm{a}}$ \\
UT & $2.67 \pm 0.05^{\mathrm{a}}$ & $2.55 \pm 0.06^{\mathrm{b}}$ & $1 \pm 0.00^{\mathrm{b}}$ \\
\hline
\end{tabular}

$\overline{\mathrm{AM}}=$ magnetic stirring; UT $=$ Ultraturra ${ }^{\circledR}$. Means \pm standard deviation $(\mathrm{SD})(p<0.05)$. Equal letters mean that there is no statistically significant difference.

The two homogenization techniques used in this study formed capsules with a continuous and homogeneous geometry represented with values close to one in the circularity parameter, which indicates that they geometrically resemble a circle. The UT treatment formed visibly and numerically smaller capsules compared with those made by AM. The morphology and microstructure of the capsules after subjecting the alginate system to different homogenization processes (AM and UT) are displayed in Figure 2. 


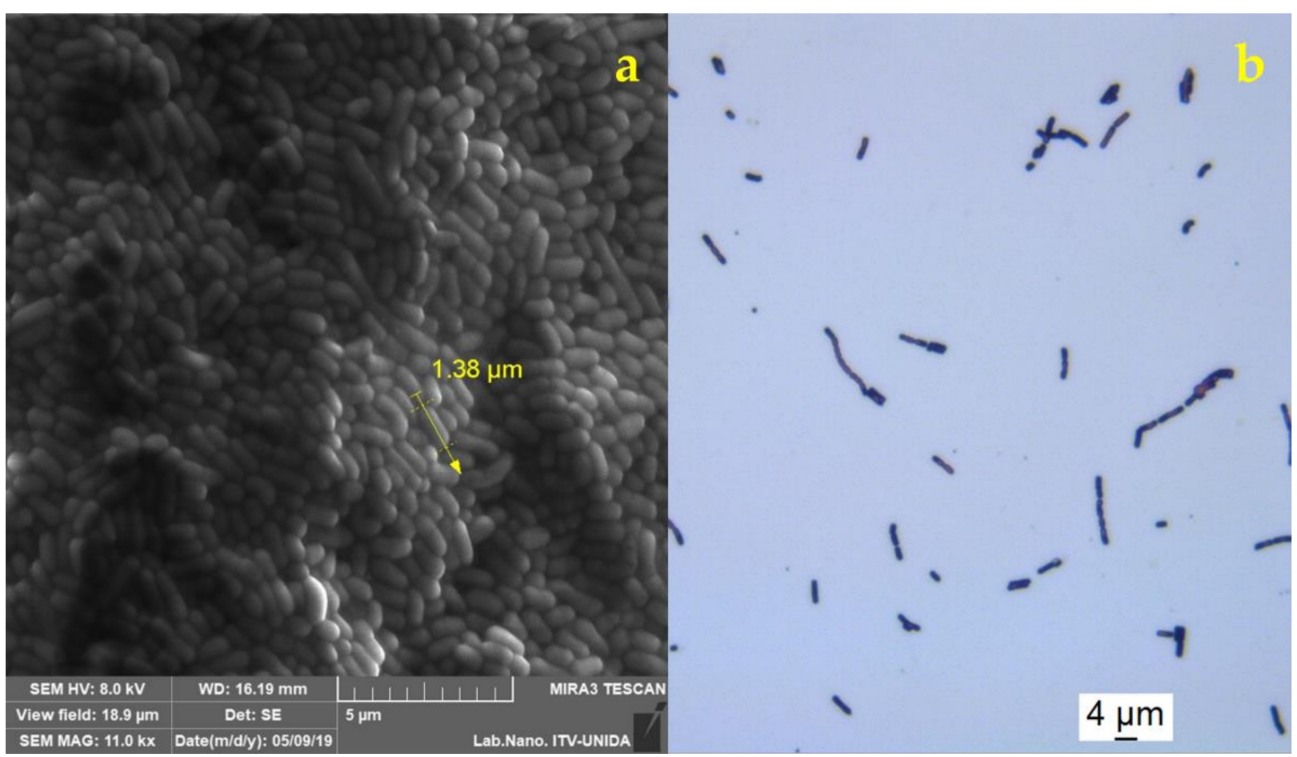

Figure 1. Micrographs of Lacticaseibacillus rhamnosus GG using: (a) scanning electron microscopy under vacuum, $11 \mathrm{kx}$ and $16 \mathrm{~mm}$ working distance, and (b) optical microscope with $100 \times$ objective.

The capsules obtained by AM showed a smooth surface compared with the rough surfaces of the capsules obtained by UT. This differentiation in the structure of the surface can be attributed to the moisture content of the samples at the moment of their visualization, even after carrying out a drying process in a laminar flow hood at room temperature. The AM capsules retained a more significant moisture content, preventing the visualization of their microstructure in detail, although with larger magnifications microspheres can be observed on its surface. It is also the case with the UT capsules. The morphology observed in the present study follows the behavior described by van Leusden et al. [34]. The capsules obtained by external gelling tend to form a layer that increases the interface strength and prevents them from shrinking or peeling. On the other hand, the appearance of microspheres, such as roughness on the surface of the capsule, is a factor that is reflected in studies using rotor-stator type equipment in the formulation of capsules [34-36].

Prasanna and Charalampopoulos [37] and Zeashan et al. [30] obtained capsules with sizes of $2.3 \mathrm{~mm}$ and $1.01 \mathrm{~mm}$, respectively, in systems made with alginate for encapsulation of Bifidobacterium longum and Lactobacillus acidophilus. Although not in their microstructure, these results are similar to those obtained in this study regarding capsule size. In the study by Prasanna and Charalampopoulos [37], a very rough surface can be seen that contrasts with the more homogeneous and smoother surface of the capsules in our study, a factor attributed to the composition of the matrix we used, suggesting that the emulsification process and its components affected the classical morphology of alginate capsules.

Silva et al. [21] obtained micrographs of capsules made by extrusion and co-extrusion with morphologies and sizes like those obtained in our study. These authors comment that the diameter of capsules produced through extrusion is generally between $1.5 \mathrm{~mm}$ and $1.9 \mathrm{~mm}$ depending on the operating conditions and the type of material used; they obtained diameters between $1.53 \mathrm{~mm}$ and $1.85 \mathrm{~mm}$ with reductions between $50 \%$ and $60 \%$ in size after being subjected to a fluidized bed drying process. The morphology of their capsules before drying was similar to that obtained in our study since a smooth and homogeneous surface can be appreciated. However, after drying, the capsules did not retain a circularity as pronounced as those obtained in our study.

Generally, in studies where it is dosed by syringes, it has been observed that alginatebased systems maintain sizes between $1 \mathrm{~mm}$ and $2.3 \mathrm{~mm}$ approximately; however, the system used in this study, due to its modifications in the components, suggests adding oil inside of the capsule, contrary to other reported systems where emulsification processes are carried out prior to ionic gelation where the oil is not part of the main structure of 
the capsule $[17,19]$. The addition of oil to the interior of the capsule is suggested to be a factor that contributes to the protection against acidic conditions through the availability of certain fatty acids but also causes a change in the morphology of the capsules [15].

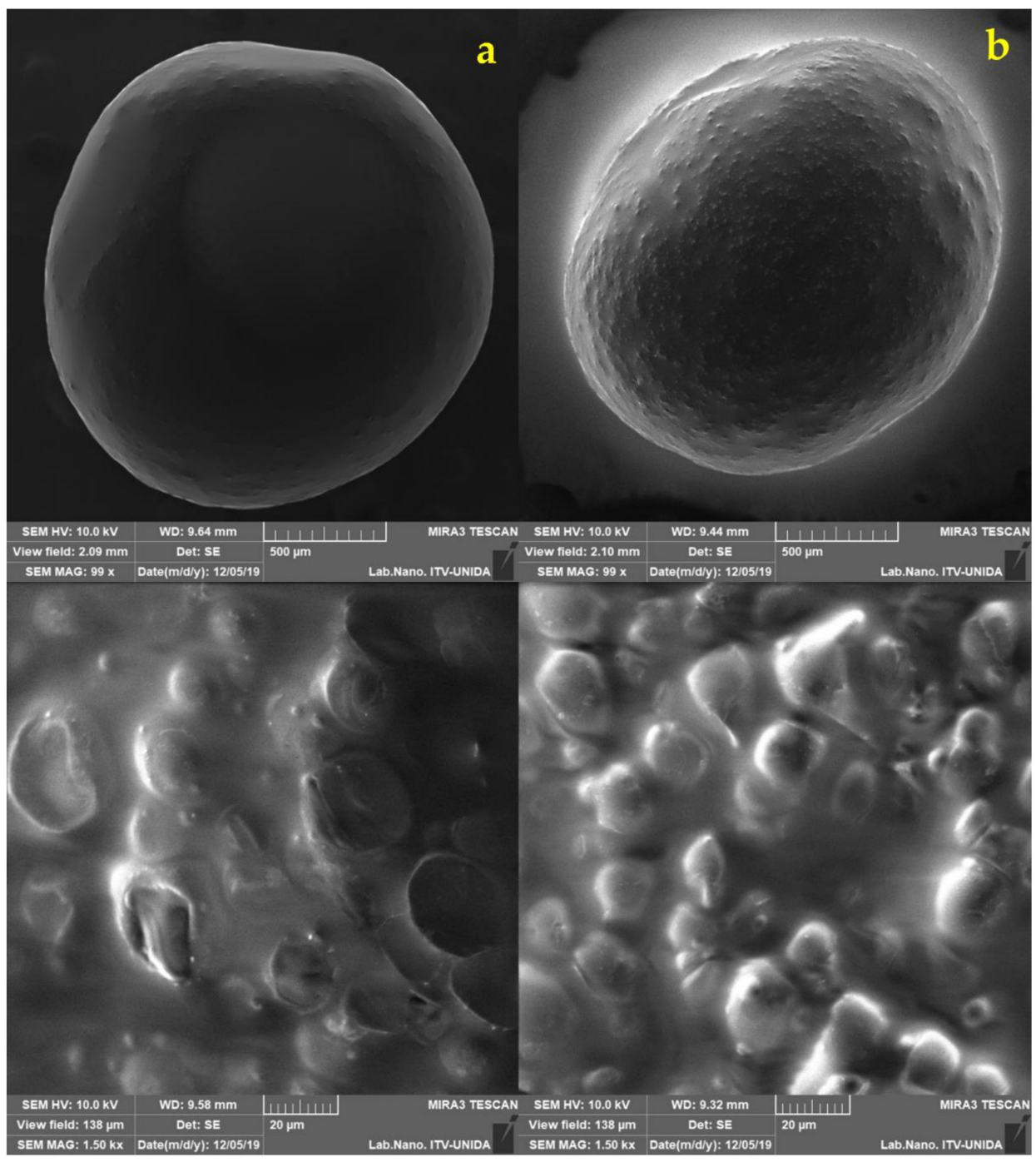

Figure 2. Micrographs were taken by SEM at $99 \mathrm{kx}$ and $1.5 \mathrm{kx}$ magnification of the AM (column (a)) and UT (column (b)) systems.

\subsection{Viability of Encapsulated Lacticaseibacillus rhamnosus GG in Simulated Gastric Conditions}

During gastric simulation, aliquots were taken at each stage to quantify the number of viable cells available. Table 3 shows the count in each stage of the in vitro simulation.

Table 3. Viability of Lacticaseibacillus rhamnosus GG: evaluation under in vitro gastrointestinal conditions of AM, UT, and free LGG.

\begin{tabular}{cccc}
\hline Method & Initial $(\log$ CFU/mL) & Final $(\log$ CFU/mL) & Viability (\%) \\
\hline AM & $6.01 \pm 0.60^{\mathrm{a}}$ & $5.84 \pm 0.80^{\mathrm{a}}$ & 97.22 \\
UT & $5.71 \pm 0.07^{\mathrm{a}}$ & $5.72 \pm 0.06^{\mathrm{a}}$ & 100 \\
Free LGG & $7.04 \pm 0.00^{\mathrm{a}}$ & $6.21 \pm 0.69^{\mathrm{b}}$ & 88.28
\end{tabular}

$\mathrm{AM}=$ magnetic stirring; $\mathrm{UT}=$ Ultraturrax $^{\circledR}$. Means \pm standard deviation $(\mathrm{SD})(p<0.05)$. Equal letters mean no statistically significant difference.

The free cells had a viability of $88.2 \%$ at the end of the gastric simulation, which was smaller than the encapsulated cells that showed $97.2 \%$ and $100 \%$ for AM and UT, 
respectively. The first two phases of the simulation (salivary and gastric) failed to degrade the capsules and produce any loss of viability in these phases. Rupture of the capsules was notorious only until the last phase (intestinal stage). This behavior was described by Guedes et al. [38], who explained that exposure of the capsules to neutral $\mathrm{pH}$ and bile salts favored the ionic exchange of the alginate's carboxyl groups, leading to destabilization in the networks that form the gel, thus deforming the matrix. Kumar and Saquib [39] reported the effect that $\mathrm{pH}$ could have on the carboxyl group $(-\mathrm{COOH})$ present in the structure of alginates that are ionically crosslinked by divalent ions such as $\mathrm{Ca}^{2+}$, being insoluble at $\mathrm{pH}$ values of less than 4.4; and on the other hand, allowing a swelling of the matrix caused by the relaxation of these carboxyl groups at $\mathrm{pH}$ close to 7.4, which is ideal for formulations intended to release compounds of interest to areas ulterior to the stomach.

An occurrence that also explains the modification of the capsules is syneresis, a chemical modification of the alginate caused by the variation of the $\mathrm{pH}$ conditions. Syneresis causes the loss of water because of the rupture of hydrogen bonds [40]. Zeashan et al. [30] reported viability of Lactobacillus acidophilus at the end of the gastric simulation of approximately $91 \%$ for their encapsulation based on alginate, and about $95.1 \%$ for their mixture with soy protein, while the free cells had a viability below $49 \%$. All three systems had viabilities below those obtained in our study, especially comparing their alginate-based encapsulation.

The probiotic survival achieved in our study is also attributed to the emulsification process that provided additional protection to the probiotic bacteria, which derived from the fatty acids present in the encapsulating mixture such as oleic acid present in Tween ${ }^{\circledR}$ 80, which according to Corcoran et al. [15] provide cellular protection when they are exposed to acidic environments. The viability of Lacticaseibacillus rhamnosus GG in this work produced good results in both encapsulated and free cells attributed to its characteristics as a bacterium with resistance to bile acids, a quality to which its prolonged survival throughout the conditions of the digestive tract can be credited [5]. Ortakci and Sert [26] suggested that sizes in the range between $1.5 \mathrm{~mm}$ and $2.5 \mathrm{~mm}$ that were obtained in their encapsulation system based on alginate result in additional protection of cells against gastrointestinal conditions caused by the increase in distance between cells and acid, thereby increasing in diffusion time. In general, the morphology and microstructure of the capsules were not affected during the first two stages of the simulation. In contrast, the capsules were deformed in the intestinal phase and lost rigidity, mainly when taking samples for microscopy analysis. To visualize the morphology of the capsules of the intestinal phase, samples were taken as in previous phases, only adding a longer drying time in the cabinet because the capsules were in a more liquid state. Still, the same visualization conditions previously described in the methodology were maintained. The properties of the encapsulating matrix allowed its morphology to be retained until the intestinal phase, making it ideal for the controlled release of probiotic bacteria at the intestine.

Figures 3 and 4 show the morphological comparison (by SEM) of the treatments and encapsulation methods in the different stages of the gastric simulation. In such Figures, bacteria adhering to the surface of the capsules can also be observed in most of the micrographs of the first two stages of the gastric simulation. In contrast, for the intestinal stage, no cells could be kept in the samples. However, these were found dispersed in the solution of the last phase according to the viability results obtained in the Petri dish count. 


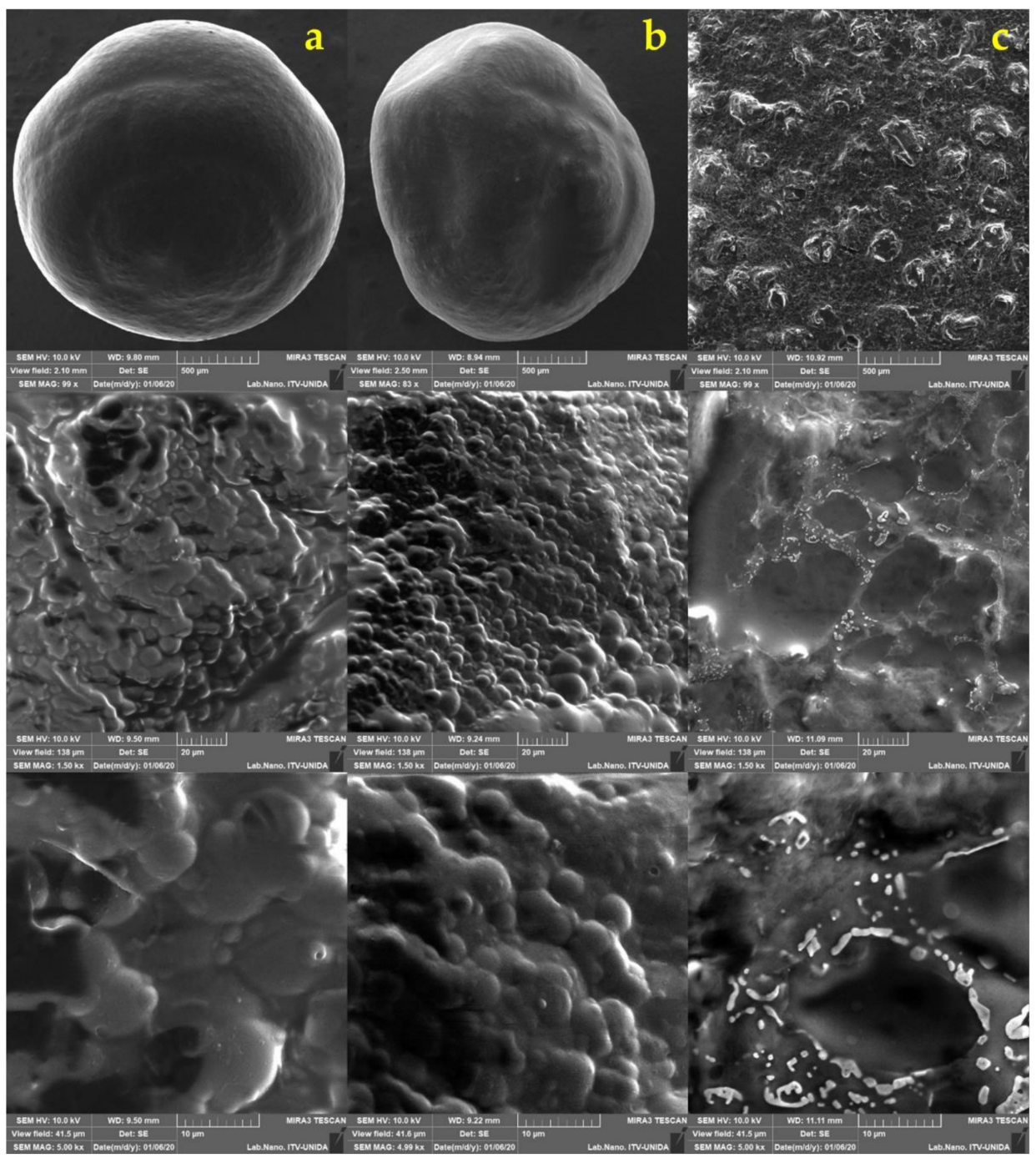

Figure 3. Encapsulated Lacticaseibacillus rhamnosus GG: UT treatment. Oral phase (column (a)), gastric phase (column (b)), and intestinal phase (column (c)).

\subsection{Viability of Lacticaseibacillus rhamnosus GG Encapsulated and Added to Food Matrices}

The viability of Lacticaseibacillus rhamnosus GG was evaluated weekly according to the method described above, dissolving $1 \mathrm{~g}$ of capsules for spreading in a Petri dish. Tables 4 and 5 show the viability results for the three and four weeks of storage of the encapsulated bacteria in apple juice and yogurt, respectively, with the AM, UT, and free LGG treatments.

Table 4. Viability of Lacticaseibacillus rhamnosus GG: AM, UT, and free LGG systems in apple juice during storage under refrigerated conditions $\left(4^{\circ} \mathrm{C}\right)$.

\begin{tabular}{cccc}
\hline Method & $\log$ CFU/mL $\left(N_{0}\right)$ & $\log$ CFU/mL $(N)$ & Viability (\%) \\
\hline AM & $5.74 \pm 0.07^{\mathrm{a}}$ & $4.94 \pm 0.04^{\mathrm{b}}$ & 86.16 \\
UT & $4.84 \pm 0.21^{\mathrm{a}}$ & $4.88 \pm 0.14^{\mathrm{a}}$ & 100.81 \\
Free LGG & $7.14 \pm 0.07^{\mathrm{a}}$ & $5.74 \pm 0.05^{\mathrm{b}}$ & 80.50 \\
\hline
\end{tabular}

$\mathrm{AM}=$ magnetic stirring; $\mathrm{UT}=\mathrm{Ultraturrax}^{\circledR}$. Means \pm standard deviation (SD) $(p<0.05)$ equal letters means that there is no statistically significant difference. 


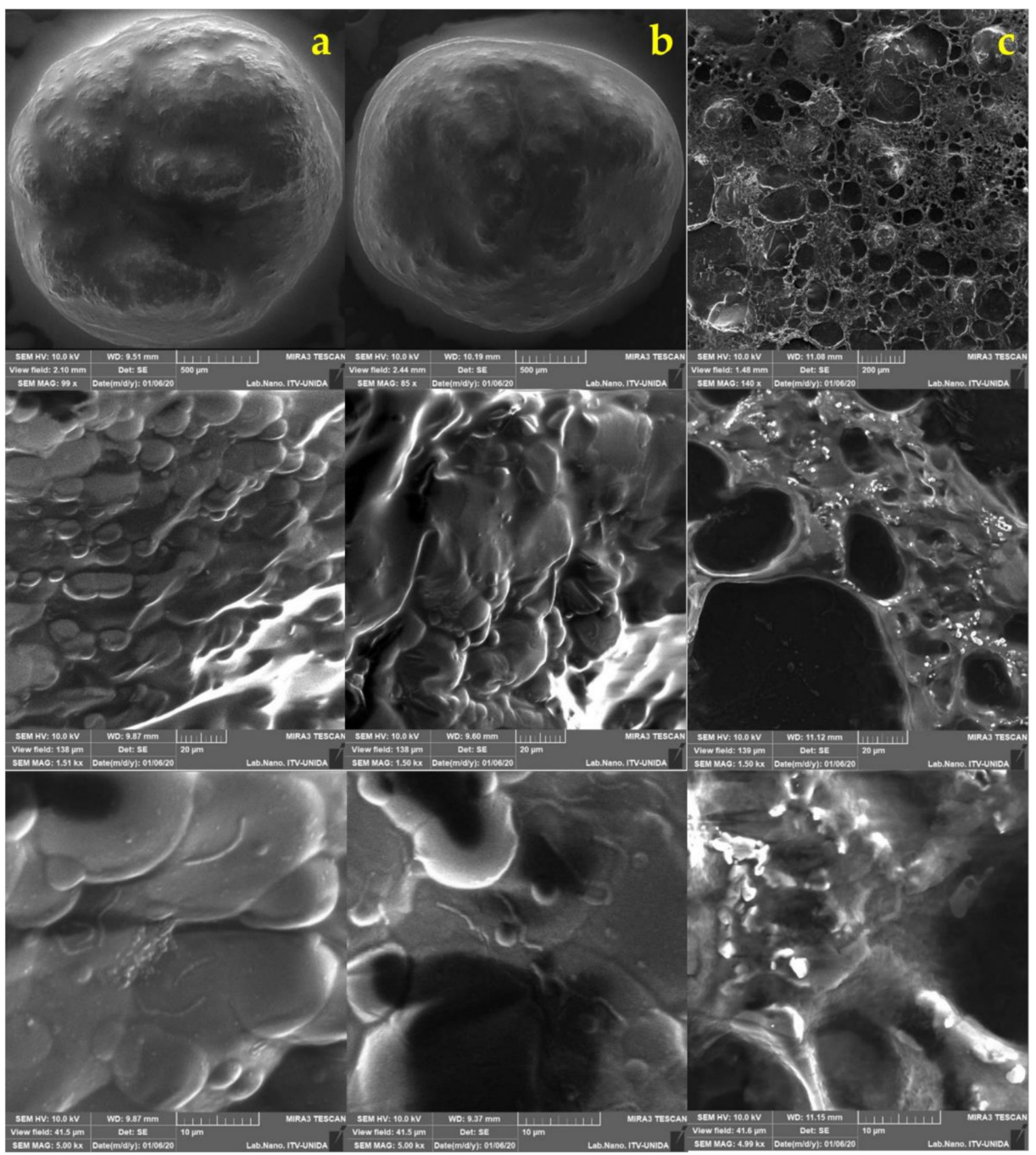

Figure 4. Encapsulated Lacticaseibacillus rhamnosus GG: AM treatment. Oral phase (column (a)), gastric phase (column (b)), and intestinal phase (column (c)).

Table 5. Viability of Lacticaseibacillus rhamnosus GG: AM, UT, and free LGG systems in yogurt during storage under refrigerated conditions $\left(4^{\circ} \mathrm{C}\right)$.

\begin{tabular}{cccc}
\hline Method & $\log$ CFU/mL $\left(\mathbf{N}_{\mathbf{0}}\right)$ & $\log$ CFU/mL (N) & Viability (\%) \\
\hline AM & $5.12 \pm 0.11^{\mathrm{a}}$ & $5.74 \pm 0.26^{\mathrm{a}}$ & 112.14 \\
UT & $5.45 \pm 0.14^{\mathrm{a}}$ & $5.56 \pm 0.02^{\mathrm{a}}$ & 102.04 \\
Free LGG & $7.04 \pm 0.00^{\mathrm{a}}$ & $6.52 \pm 0.01^{\mathrm{b}}$ & 92.54 \\
\hline
\end{tabular}

$\mathrm{AM}=$ magnetic stirring; $\mathrm{UT}=\mathrm{Ultraturrax}^{\circledR}$. Means \pm standard deviation (SD) $(p<0.05)$ equal letters means that there is no statistically significant difference.

The decline in viable cells is attributed to substrate depletion and the antagonistic effect that dead cells can have by releasing enzymes that hydrolyze sugars in the medium and exposure to low $\mathrm{pH}$ for extended periods [41]. On the other hand, the survival of the encapsulated cells can be ascribed to the fact that the transition of acids and flavonoids typical of the juice towards the capsule's interior is impeded by the presence of a protective encapsulating matrix such as alginate [24]. Lacticaseibacillus rhamnosus GG is resistant to environments with $\mathrm{pH}$ up to 2.5 , which is reflected in its survival in juices in the free state $[42,43]$. The capsules can provide a favorable environment for bacteria and a physical barrier against environmental conditions that may affect their viability [44]. In the results of Lacticaseibacillus rhamnosus GG encapsulated in yogurt (Table 5), the counts for three weeks showed slight cell growth for both UT and AM, a phenomenon attributed 
to the permeability or degradation of the alginate capsules allowing bacteria to consume the substrate available in the food. Ding and Shah [44] present in their study viability of Lacticaseibacillus rhamnosus encapsulated and added to orange juice stored at $4{ }^{\circ} \mathrm{C}$ of approximately $80 \%$ at the end of the third week, while the viability of the free cell was $75 \%$. These results show similarities with those obtained in the present study of the AM systems and free cells, being $86.16 \%$ and $80.5 \%$, respectively, but not with those obtained by the UT System, which had 100\% viability at the end of the evaluation. Ortakci and Sert [26] analyzed the viability of Lactobacillus acidophilus ATCC 4356 encapsulated and added to yogurt during storage at $4{ }^{\circ} \mathrm{C}$, obtaining viability data for their encapsulated system of $86.68 \%$ and $90 \%$ for free cells. The viability of the free cells had values close to the results obtained in this study; however, the encapsulated systems differ in the values presented by AM and UT systems, being higher than those obtained in our work. They highlighted that high probiotic survival could be attributed to the size of the capsules, the strain used, or to post-acidification processes during storage, related to the diffusion capacity of components within and outside the capsule caused by the porosity of the alginate, which suggests that the passage of nutrients can be used by the encapsulated bacteria favored their viability during the storage process [45]. Figures 5-8 show the micrographs of the capsules during their storage in juice and yogurt obtained by SEM.

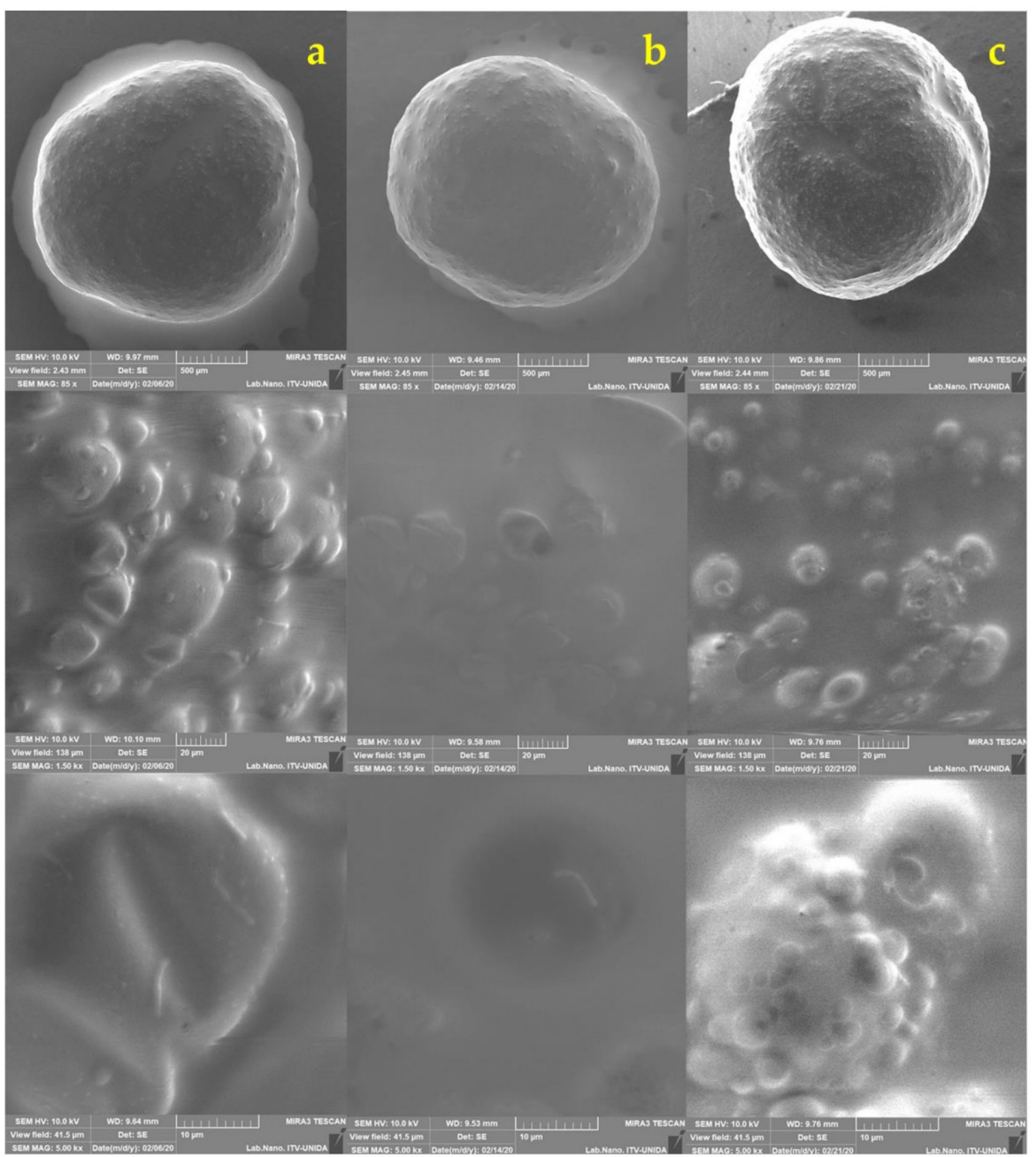

Figure 5. Encapsulated Lacticaseibacillus rhamnosus GG: AM treatment in apple juice: 7 days (column (a)), 15 days (column (b)), and 22 days (column (c)). 


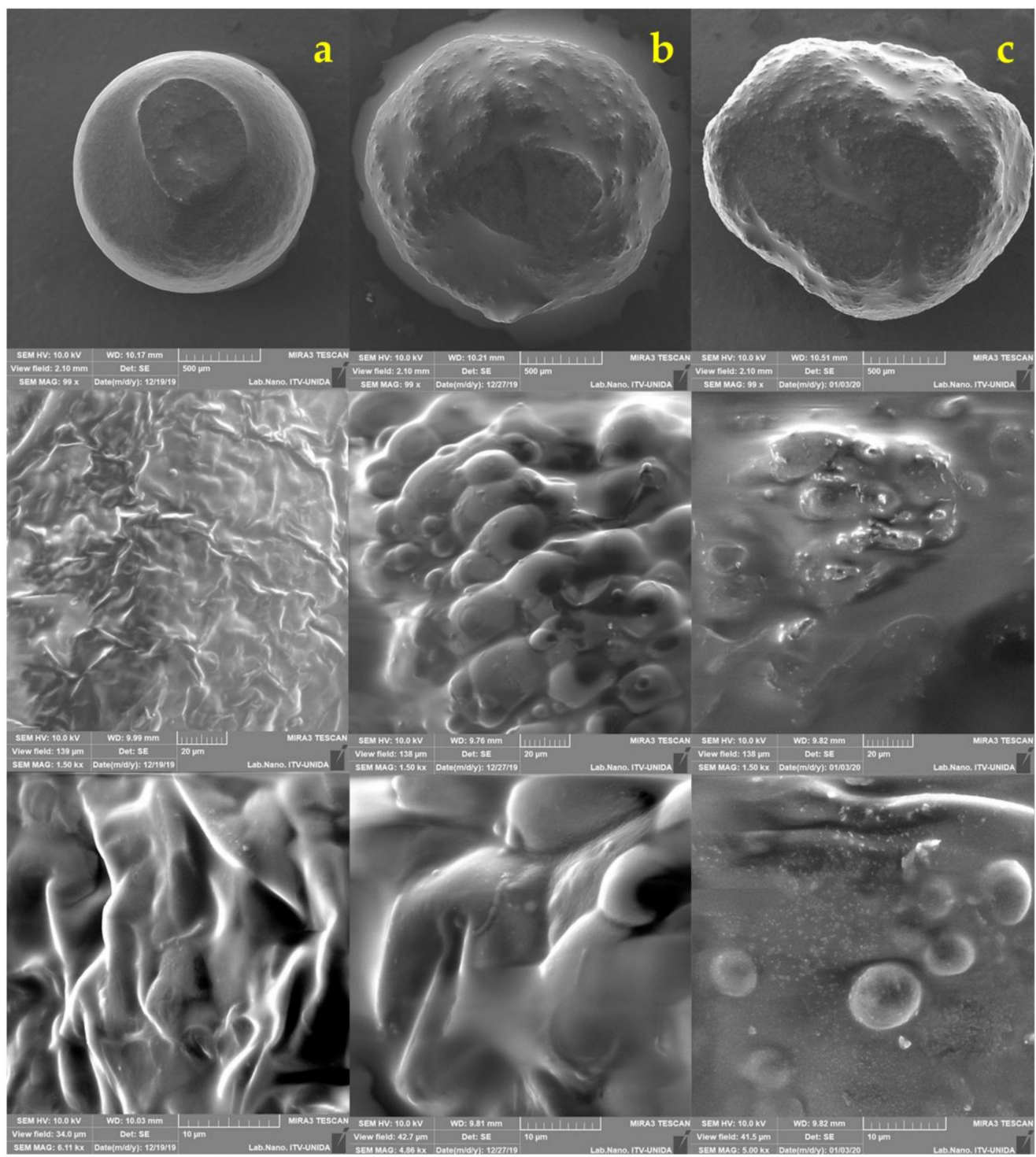

Figure 6. Encapsulated Lacticaseibacillus rhamnosus GG: AM treatment in yogurt: 15 days (column (a)), 22 days (column (b)), and 30 days (column (c)).

During their evaluation, the capsules did not show macroscopic differences. The alginate capsules exhibited resistance and stability until the second week of the study. When exposed to SEM, the electron beam likely managed to pierce the capsules, thus releasing the components after a prolonged focus time. However, the encapsulation and the wall material can offer protection to the bacterial cells against conditions that could affect their viability, such as the stress that the gastrointestinal tract may cause when consuming a food inoculated with probiotics or due to the shear forces caused by the homogenization processes $[19,46,47]$. 


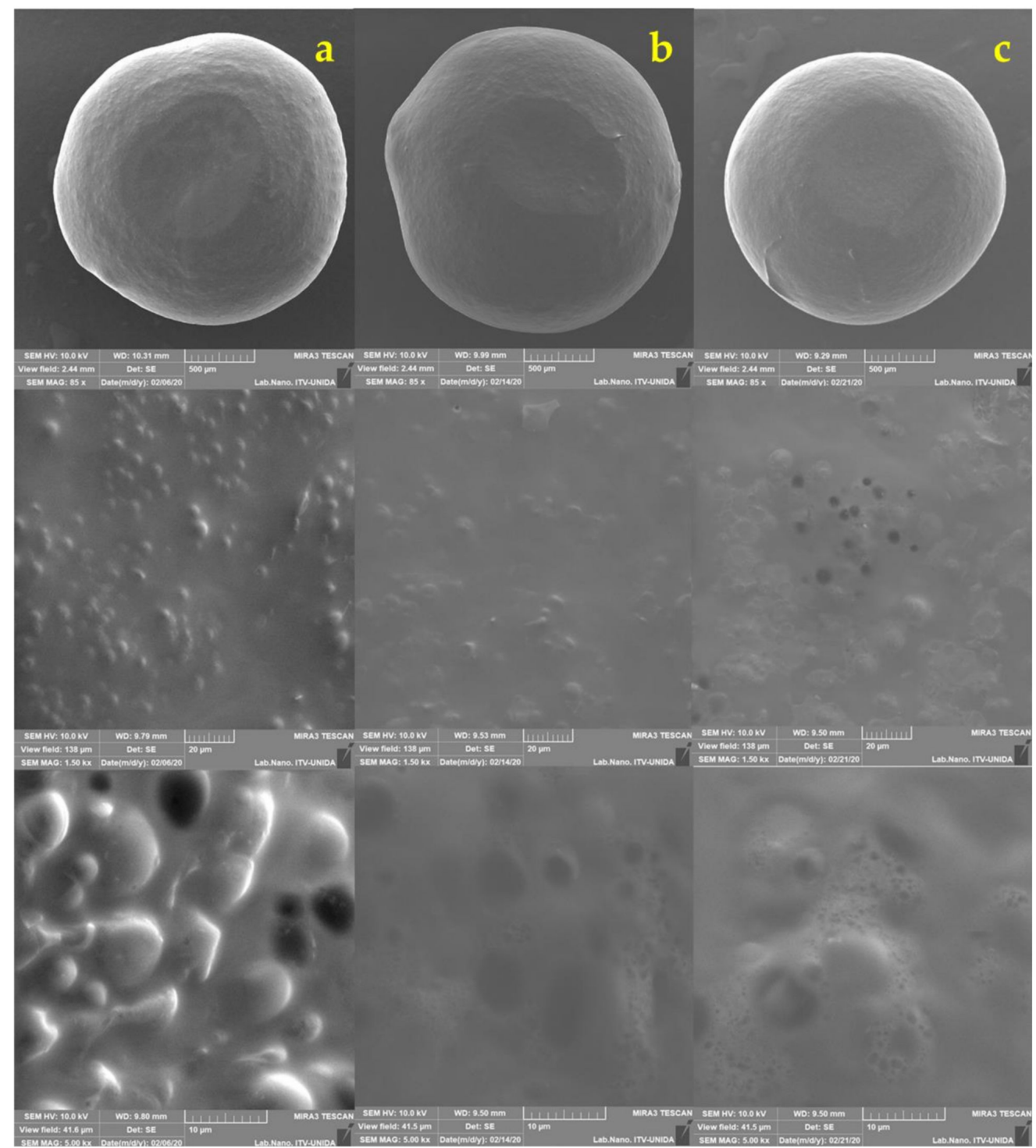

Figure 7. Encapsulated Lacticaseibacillus rhamnosus GG: UT treatment in apple juice: 7 days (column (a)), 15 days (column (b)), and 22 days (column (c)). 


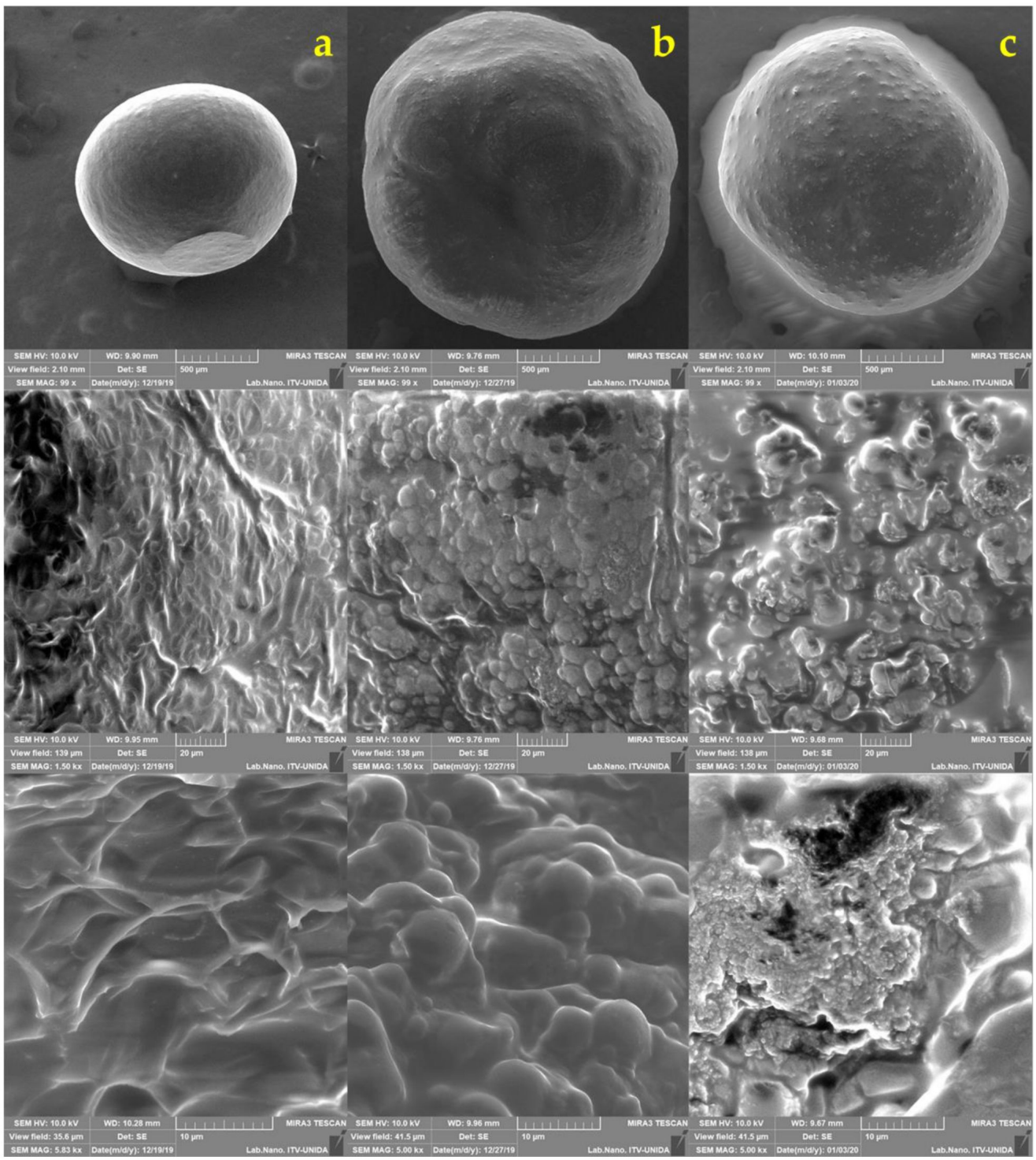

Figure 8. Encapsulated Lacticaseibacillus rhamnosus GG: UT treatment in yogurt: 15 days (column (a)), 22 days (column (b)), and 30 days (column (c)).

\section{Conclusions}

Regarding the encapsulation process, the best treatment was UT at $4000 \mathrm{rpm}$ for $7.5 \mathrm{~min}$, with bacterial viability greater than $85.80 \%$. The LGG concentrations in the capsules made by AM and UT exceed the minimum consumption recommendations to have a beneficial effect on health. The morphology of the capsules from the AM was mostly regular and homogeneous. In contrast, in the case of the UT, a rough surface with microcapsules was observed. However, the UT was the treatment that produced circularity values near one and a smaller size compared with the AM. Under this principle, spraying techniques can be proposed to reduce the droplet size and increase the contact area. The encapsulation process carried out in this study provided LGG an environment resistant to gastric- simulated conditions showing a viability of $100 \%$ at the end of the intestinal phase with the best treatment, while in free bacteria, viability was $88.2 \%$. The formulation of the encapsulating mixture turned out to be adequate for the protection of probiotic bacteria against stress conditions. The high percentages of viability obtained suggest that some characteristics of the matrix, as the case of fatty acids present in the oil and in the Tween ${ }^{\circledR}$, can be used by bacteria to increase their viability with respect to systems formulated only with alginate described by various authors. Scanning electron 
microscopy verified the presence of LGG cells on the surface of the capsule even after its evaluation under simulated gastric conditions. This phenomenon can also be attributed to the gradual degradation of the matrix in each simulation stage and the degradative effect of the incidence of the electron beam to the capsules during the morphological analysis. The use of an encapsulation system allowed to preserve cell viability for more than three weeks in two food matrices with distinct characteristics, which represents a practical alternative for the preservation and addition of probiotic bacteria in foods of different nature to make them functional or enhance their beneficial effect, in addition to providing a controlled release of bacteria once these foods are ingested. On the other hand, the use of an emulsification process prior to the ionic gelation of the alginate gives favorable morphological and functional characteristics; however, more studies should be pursued on the interactions between the compounds of the mixture as well as the implementation of particle size reduction techniques to improve the sensory qualities of the products to which they can be added.

Author Contributions: Conceptualization, O.O.R.-C., A.V.-P. and C.C.-S.; data curation, P.J.G.-R.; formal analysis, A.G.C.-O. and P.J.G.-R.; funding acquisition, C.C.-S.; investigation, O.O.R.-C. and A.V.-P.; methodology, O.O.R.-C., A.V.-P., J.S. and C.Y.F.-H.; resources, H.S.G., R.V.-C., C.Y.F.-H. and C.C.-S.; software, A.G.C.-O. and P.J.G.-R.; supervision, C.Y.F.-H. and C.C.-S.; validation, A.G.C.-O.; visualization, H.S.G.; writing —original draft, O.O.R.-C. and A.V.-P.; writing—review and editing, H.S.G., J.S., R.V.-C., C.Y.F.-H. and C.C.-S. All authors have read and agreed to the published version of the manuscript.

Funding: This research was financed by Consejo Veracruzano de Investigación Científica y Desarrollo Tecnológico (COVEICYDET).

Institutional Review Board Statement: Not applicable.

Informed Consent Statement: Not applicable.

Data Availability Statement: The authors declare the transparency of data.

Acknowledgments: Authors Oscar Osiel Romero-Chapol and Abigail Varela-Pérez want to thank the Consejo Nacional de Ciencia y Tecnología (CONACYT) for the master's scholarships. Ana Guadalupe Castillo-Olmos also thanks CONACYT for her doctoral scholarship. We also thank Isaac Osuna-Marmolejo for the micrographs.

Conflicts of Interest: The authors declare no conflict of interest. The funders had no role in the design of the study; in the collection, analyses, or interpretation of data; in the writing of the manuscript, or in the decision to publish the results.

\section{References}

1. FAO/WHO. Guidelines for the Evaluation of Probiotics in Food. Available online: https://www.who.int/foodsafety/fs_ management/en/probiotic_guidelines.pdf (accessed on 17 December 2021).

2. Ji, Y.; Park, S.; Park, H.; Hwang, E.; Shin, H.; Pot, B.; Holzapfel, W.H. Modulation of Active Gut Microbiota by Lactobacillus rhamnosus GG in a Diet Induced Obesity Murine Model. Front. Microbiol. 2018, 9, 710. [CrossRef] [PubMed]

3. Kim, B.; Park, K.; Ji, Y.; Park, S.; Holzapfel, W.; Hyun, C. Protective effects of Lactobacillus rhamnosus GG against dyslipidemia in high-fat diet-induced obese mice. Biochem. Biophys. Res. Commun. 2016, 473, 530-536. [CrossRef]

4. Shin, J.; Nam, M.; Lee, H.; Lee, J.; Kim, H.; Chung, M.; Seo, J. Amelioration of obesity-related characteristics by a probiotic formulation in a high-fat diet-induced obese rat model. Eur. J. Nutr. 2017, 57, 2081-2090. [CrossRef] [PubMed]

5. Segers, M.E.; Lebeer, S. Towards a better understanding of Lactobacillus rhamnosus GG-host interactions. Microb. Cell Fact. 2014, 13, 1-16. [CrossRef] [PubMed]

6. Yang, I.; Corwin, E.J.; Brennan, P.A.; Jordan, S.; Murphy, J.R.; Dunlop, A. The Infant Microbiome. Nurs. Res. 2016, 65, 76-88. [CrossRef]

7. Lifeder. Lactobacillus rhamnosus: Características, Morfología. Available online: https://www.lifeder.com/lactobacillusrhamnosus/ (accessed on 23 July 2020).

8. Cheng, Y.; Liu, J. Effect of Lactobacillus rhamnosus GG on Energy Metabolism, Leptin Resistance, and Gut Microbiota in Mice with Diet-Induced Obesity. Nutrients 2020, 12, 2557. [CrossRef]

9. Markowiak-Kopeć, P.; Śliżewska, K. The Effect of Probiotics on the Production of Short-Chain Fatty Acids by Human Intestinal Microbiome. Nutrients 2020, 12, 1107. [CrossRef] 
10. Reque, P.M.; Brandelli, A. Encapsulation of probiotics and nutraceuticals: Applications in functional food industry. Trends Food Sci. Technol. 2021, 114, 1-10. [CrossRef]

11. Misra, S.; Pandey, P.; Mishra, H.N. Novel approaches for co-encapsulation of probiotic bacteria with bioactive compounds, their health benefits and functional food product development: A review. Trends Food Sci. Technol. 2021, 109, 340-351. [CrossRef]

12. De Araújo, U.N.; Gutiérrez, R.L.; Ruiz, V.O.; Montoya, C.O. Técnicas para la microencapsulación de probióticos y el impacto en su funcionalidad: Una revisión. Aliment. Hoy 2015, 23, 112-126.

13. Yilmaz, M.T.; Taylan, O.; Karakas, C.Y.; Dertli, E. An alternative way to encapsulate probiotics within electrospun alginate nanofibers as monitored under simulated gastrointestinal conditions and in kefir. Carbohydr. Polym. 2020, 244, 116447. [CrossRef]

14. Brownlee, I.A.; Allen, A.; Pearson, J.P.; Dettmar, P.W.; Havler, M.E.; Atherton, M.R.; Onsøyen, E. Alginate as a Source of Dietary Fiber. Crit. Rev. Food Sci. Nutr. 2005, 45, 497-510. [CrossRef] [PubMed]

15. Corcoran, B.M.; Stanton, C.; Fitzgerald, G.F.; Ross, R.P. Growth of probiotic lactobacilli in the presence of oleic acid enhances subsequent survival in gastric juice. Microbiology 2007, 153, 291-299. [CrossRef] [PubMed]

16. De Araújo, E.M.; Lorenzoni, N.G.; Righi, N.B.; Smanioto, B.J.; Moraes, F.E.; Olivera, M.R.; Ragagnin, M.C. Improvement of the viability of encapsulated probiotics using whey proteins. LWT Food Sci. Technol. 2020, 117, 108601. [CrossRef]

17. Ding, W.K.; Shah, N.P. Effect of homogenization techniques on reducing the size of microcapsules and the survival of probiotic bacteria therein. J. Food Sci. 2009, 74, 231-236. [CrossRef]

18. Seth, D.; Mishra, H.; Deka, S. Effect of microencapsulation using extrusion technique on viability of bacterial cells during spray drying of sweetened yoghurt. Int. J. Biol. Macromol. 2017, 103, 802-807. [CrossRef]

19. Patrignani, F.; Siroli, L.; Serrazanetti, D.I.; Braschi, G.; Betoret, E.; Reinheimer, J.A.; Lanciotti, R. Microencapsulation of functional strains by high pressure homogenization for a potential use in fermented milk. Food Res. Int. 2017, 97, 250-257. [CrossRef]

20. Colín-Cruz, M.A.; Pimentel-González, D.J.; Carrillo-Navas, H.; Álvarez-Ramírez, J.; Guadarrama-Lezama, A.Y. Co-encapsulation of bioactive compounds from blackberry juice and probiotic bacteria in biopolymeric matrices. LWT Food Sci. Technol. 2019, 110, 94-101. [CrossRef]

21. Silva, M.P.; Tulini, F.L.; Martins, E.; Penning, M.; Fávaro-Trindade, C.; Poncelet, D. Comparison of extrusion and co-extrusion encapsulation techniques to protect Lactobacillus acidophilus LA3 in simulated gastrointestinal fluids. LWT Food Sci. Technol. 2018, 89, 392-399. [CrossRef]

22. Zazzali, I.; Aguirre, C.; Pizones, R.; Santagapita, P.R.; Perullini, M. Effects of pH, extrusion tip size and storage protocol on the structural properties of Ca (II) alginate beads. Carbohydr. Polym. 2019, 206, 749-756. [CrossRef]

23. Dorożyński, P.; Kulinowski, P.; Mendyk, A.; Młynarczyk, A.; Jachowicz, R. Novel application of MRI technique combined with flow-through cell dissolution apparatus as supportive discriminatory test for evaluation of controlled release formulations. AAPS PharmSciTech. 2010, 11, 588-597. [CrossRef] [PubMed]

24. Gandomi, H.; Abbaszadeh, S.; Misaghi, A.; Bokaie, S.; Noori, N. Effect of chitosan-alginate encapsulation with inulin on survival of Lactobacillus rhamnosus GG during apple juice storage and under simulated gastrointestinal conditions. LWT Food Sci. Technol. 2016, 69, 365-371. [CrossRef]

25. Perricone, M.; Corbo, M.R.; Sinigaglia, M.; Speranza, B.; Bevilacqua, A. Viability of Lactobacillus reuteri in fruit juices. J. Funct. Foods 2014, 10, 421-426. [CrossRef]

26. Ortakci, F.; Sert, S. Stability of free and encapsulated Lactobacillus acidophilus ATCC 4356 in yoghurt and in an artificial human gastric digestion system. J. Dairy Sci. 2012, 95, 6918-6925. [CrossRef]

27. Minekus, M.; Alminger, M.; Alvito, P.; Ballance, S.; Bohn, T.; Bourlieu, C.; Carrière, F.; Boutrou, R.; Corredig, M.; Dupont, D.; et al. A Standardised static in vitro digestion method suitable for food-an international consensus. Food Funct. 2014, 5, 1113-1124. [CrossRef]

28. Cano, M.P.; Gómez-Maqueo, A.; Fernández-López, R.; Welti-Chanes, J.; García- Cayuela, T. Impact of high hydrostatic pressure and thermal treatment on the stability and bioaccessibility of carotenoid and carotenoid esters in astringent persimmon (Diospyros kaki Thunb, var. Rojo Brillante). Food Res. Int. 2019, 123, 538-549. [CrossRef]

29. Ribeiro, M.; Chaves, K.; Gebara, C.; Infante, F.; Grosso, C.; Gigante, M. Effect of microencapsulation of Lactobacillus acidophilus LA-5 on physicochemical, sensory and microbiological characteristics of stirred probiotic yoghurt. Food Res. Int. 2014, 66, 424-431. [CrossRef]

30. Zeashan, M.; Afzaal, M.; Saeed, F.; Ahmed, A.; Tufail, T.; Ahmed, A.; Muhammad, A.F. Survival and behavior of free and encapsulated probiotic bacteria under simulated human gastrointestinal and technological conditions. Food Sci. Nutr. 2020, 8 , 2419-2426. [CrossRef]

31. Sánchez, M.T.; Ruiz, M.A.; Lasserrot, A.; Hormigo, M.; Morales, M.E. An improved ionic gelation method to encapsulate Lactobacillus spp. bacteria: Protection, survival and stability study. Food Hydrocoll. 2017, 69, 67-75. [CrossRef]

32. Capela, P.; Hay, T.K.C.; Shah, N.P. Effect of homogenisation on bead size and survival of encapsulated probiotic bacteria. Food Res. Int. 2007, 40, 1261-1269. [CrossRef]

33. Zhang, L.; Xu, Y.; Liu, H.; Lai, T.; Ma, J.; Wang, J.; Zhu, Y. Evaluation of Lactobacillus rhamnosus GG using an Escherichia coli K88 model of piglet diarrhoea: Effects on diarrhoea incidence, faecal microflora and immune responses. Vet. Microbiol. 2010, 141, 142-148. [CrossRef]

34. Van Leusden, P.; den Hartog, G.J.M.; Bast, A.; Postema, M.; van der Linden, E.; Sagis, L.M.C. Strength of microbeads for the encapsulation of heat sensitive, hydrophobic components. Food Hydrocoll. 2016, 56, 318-324. [CrossRef] 
35. Paques, J.P.; van der Linden, E.; van Rijn, C.J.M.; Sagis, L.M.C. Alginate submicron beads prepared through w/o emulsification and gelation with $\mathrm{CaCl}_{2}$ nanoparticles. Food Hydrocoll. 2013, 31, 428-434. [CrossRef]

36. Huq, T.; Fraschini, C.; Khan, A.; Riedl, B.; Bouchard, J.; Lacroix, M. Alginate based nanocomposite for microencapsulation of probiotic: Effect of cellulose nanocrystal (CNC) and lecithin. Carbohydr. Polym. 2017, 168, 61-69. [CrossRef] [PubMed]

37. Prasanna, P.; Charalampopoulos, D. Encapsulation of Bifidobacterium longum in alginate-dairy matrices and survival in simulated gastrointestinal conditions, refrigeration, cow milk and goat milk. Food Biosci. 2018, 21, 72-79. [CrossRef]

38. Guedes, S.; Cezarino, E.; Michelon, M.; Kawazoe, S. Symbiotic microencapsulation to enhance Lactobacillus acidophilus survival. LWT Food Sci. Technol. 2018, 89, 503-509.

39. Kumar, N.A.; Saquib, H.M. Alginates in Drug Delivery, 1st ed.; Academic Press: San Diego, CA, USA, $2020 ;$ pp. 1-416.

40. Helgerud, T.; Gåserød, O.; Fjæreide, T.; Andersen, P.; Larsen, C. Alginates. In Food Stabilisers, Thickeners and Gelling Agents, 1st ed.; Imeson, A., Ed.; Wiley-Blackwell: Oxford, UK, 2010; pp. 50-69.

41. Mokhtari, S.; Jafari, S.M.; Khomeiri, M. Survival of encapsulated probiotics in pasteurized grape juice and evaluation of their properties during storage. Food Sci. Technol. Int. 2018, 25, 120-129. [CrossRef]

42. Corcoran, B.M.; Stanton, C.; Fitzgerald, G.F.; Ross, R.P. Survival of probiotic lactobacilli in acidic environments is enhanced in the presence of metabolizable sugars. Appl. Environ. Microbiol. 2005, 71, 3060-3067. [CrossRef]

43. Cueto-Vigil, M.; Acuña-Monsalve, Y.; Valenzuela-Riaño, J. In Vitro evaluation of probiotic potential of lactic bacteria acid isolated from Coastal serum. Actu. Biol. 2010, 32, 129-138.

44. Ding, W.K.; Shah, N.P. Survival of free and microencapsulated probiotic bacteria in orange and apple Juices. Int. Food Res. J. 2008, 15, 219-232.

45. Van Leusden, P.; den Hartog, G.J.M.; Bast, A.; Postema, M.; van der Linden, E.; Sagis, L.M.C. Permeation of probe molecules into alginate microbeads: Effect of salt and processing. Food Hydrocoll. 2017, 73, 255-261. [CrossRef]

46. Kailasapathy, K. Survival of free and encapsulated probiotic bacteria and their effect on the sensory properties of yoghurt. LWT Food Sci. Technol. 2006, 39, 1221-1227. [CrossRef]

47. Yoha, K.S.; Nida, S.; Dutta, S.; Moses, J.A.; Anandharamakrishnan, C. Targeted delivery of probiotics: Perspectives on research and commercialization. Probiotics Antimicrob. Proteins 2021, 1-34. [CrossRef] [PubMed] 